\section{Congenital Central Alveolar Hypoventilation Syndrome}

Helga Peter ${ }^{1}$ und Thomas Penzel ${ }^{2}$

${ }^{1}$ Marburg, Deutschland

${ }^{2}$ Interdisziplinäres Schlafmedizinisches Zentrum, Charité Universitätsmedizin Berlin, Berlin, Deutschland

\section{Definition}

Kongenitales zentral-alveoläres Hypoventilationssyndrom. Siehe auch

- „Schlafbezogene Hypoventilationssyndrome“

- „Schlafbezogene Hypoxämie“

\title{
Synonyme
}

$\mathrm{CCAH}$ 